sphere laden with aqueous vapour on the colour of the hill in the background.

268. "The Alps at Rosenlaui"--V. Cole, A. Gloriously true. The fading of colour in the distant bosses is perfectly rendered--the depth of the atmosphere can be gauged.

306. "Struyve Rocks, coast of Arran"-Geo. E. Hering. A red sunset, nearly perfect in colour from top to bottom; if the yellow had faded into green it would have been better. Compare red with 353 .

324. "Conway Marsh"-Jos. Knight. Sunset green, and deep blue hill admirable, but I doubt the colour of the foreground.

405. "Gleaners"-H. R. Robertson. Red, yellow, green, good. Moon nearly right, which is wonderful. (This by the way).

587. "Shining after Rain: Loch Etive"-Geo. E. Hering. The work of a careful observer.

615. "The Lowing Herd winds slowly o'er the Lea" -H. W. B. Davis, R.A. Perfect sunset (poor moon!). (Again by the way).

647. "An Autumn Walk"-A. E. Emslie. Good red and yellow.

739. "Sunset on the Jungfrau, Mönch, and Eiger"Jas. W. Smith. The blue below and red above on the snow perfectly rendered.

788. "The Written Valley, Wilderness of Sinai"Henry A. Harper. Good, but not so good as 739 .

I next come to those pictures which I think are inaccurate in colour.

86. "Christiana with her Family, accompanied by Mercy, arrive at the Slough of Despond: Mercy finds a way across"-R. Thorburn, A. Impossible cloud colours. Clouds bluer than sky and atmosphere nowhere.

146. "Solitude"-P. F. Poole, R.A. Impossible green sky and cloud.

20I. B. Riviere, A. Unnatural moonlight and impossible pea-soup shadows. The softness and colour of the latter suggest that $\mathrm{Mr}$. Riviere has never studied moonlight.

23r. "David, the Future King of Israel, while a Shepherd at Bethlehem "-J. R. Herbert, R.A. Colour impossible both in quantity and quality.

240. "A Dream of Ancient Egypt: the Morning of the Exodus"-Andrew MacCallum. I should like to hear the painter lecture on the connection of the colours of bodies with the light which falls upon them.

298. "Jarl Hacon in the Pentland Firth"-J. Hope M'Lachlan. High blotches of red over green and yellow impossible, and brick-dust beams of light proceeding from nothing still more impossible.

309. "The Sunrise Gun, Castle Cornet, Guernsey"Tristram Ellis. Sky colour good; impossible colour of water under sky conditions given.

353. "After the Rain"--W. H. W. Foster. Unnatural sunset, colour and distribution of light wrong.
424. "The Last Journey"-Clara Montalba. Impossible green sky; the sun is neither setting nor set.

483. "An Autumn Sunrise" - Cecil G. Lawson. Interesting as a foretaste of the future when the sun shall have cooled.

525. A. Dixon. Green hopelessly wrong.

542. "The Dee Sands"-J. W. Oakes;, A. Sky colours impossible with so bigh a sun.

555. "The Last of the Wreck"-E. Ellis. Green clouds!

630. "An Incident by the Wayside"-Mark Anthony. Impossible blue sky.

These, then, are the pictures I shall use as texts in my future notes. J. NORMAN LOCKYER

\section{THE AMERICAN STORM WARNINGS}

T HAVE now to direct attention to "Atlantic Storms,Whence they come and where they go?" All storms that cross the Atlantic Ocean to the coasts of Europe come from the equatorial zone of the Atlantic from the Pacific Ocean, or are developed from depressions on the American continent by peculiar operations of the law of atmospheric movements. The most prolific source of storms for the field of observation just sketched is the Pacific, but all the disturbances coming thence do not necessarily originate there. As I have stated, storms pass over the Pacific from the Asiatic as they do from the American continent over the Atlantic, but generally in more northerly latitudes. Their number cannot be accurately determined until a similar system of observation to that now in operation from the West Indies to Newfoundland is organised on the Eastern coast of Asia. As it is we are dependent on observations made along the Pacific coasts of the United States, British territory, Mexico, and the Central American States, for information regarding the arrival of storms from the westward on this continent. Fortunately the observers are now numerous enough to constitute an effective guard against the possibility of even a small storm centre passing inland unnoticed. These coast observations furnish reliable evidence of the fact that storms arrive on this continent from the Pacific much in the same manner as Atlantic storms reach Europe. It is my purpose to trace as closely as possible the movements of the various types of storms that originate in or cross the Atlantic from west to east, and I will begin with those whose first appearance is observed on the Pacific coast of the United States.

It has been noticed that storm areas approach these Pacific coasts as large depressions with a comparatively low energy of rotation around their centres. But when the area reaches the line of the coast or cascade range of mountains in Oregon and Washington territory, its outline is changed from the distorted circular to that of the irregular elliptical, and the northern end of the latter figure is carried toward the coast line more rapidly than the southern one, causing, as a rule, the first rainfall in the line of first contact with the land. Therefore, over Vancouver's Island and Western Oregon a rapid condensation of atmospheric moisture takes place which so : Continued from p. 7 . 
speedily exhausts the air volume immediately affected by the storm of its humidity, that the lines of equal annual rainfall on this section of the coast are very close together, marking a decrease of precipitation inland. The energy of rotation increases here as the pressure at the storm centre falls. This energy concentrates at the northern end of the depression, and the area of low barometer is crawn, as it were, around the centre so formed as it passes eastward over the first range of mountains. After passing over all the intervening ranges of the great plateau toward the line of the Rocky Mountains in Montana and the British territory northward thereof, the storm as a moving atmospheric vortex is attended by only a very little rain or snow. The'region over which it passes cannot furnish any supply of humid air, and the storm becomes again disorganised into a great depression during and after its passage over the mountains, until its centre has reached the eastern slopes. But here it enters a new region so circumstanced in its topographical relations with the east and south, as to derive a full and uninterrupted flow of humid air from the great river valleys, the lake regions, and the distant Gulf of Mexico. There are no intervening mountain barriers between these sources of humidity and the north-western prairies to interrupt the atmospheric flow toward the depression extending over them, but the storm reorganises slowly at first as the conditions necessary to induce a strong indraught of air to its centre are of very gradual development. When, however, they come into requisite combination, the indraught winds increase, and coming from the north-east and east, are deflected southward and south-eastward by the mountains, until a feeble but decided vortex is developed in the centre of the depression. The centripetal winds now begin to increase with the inflow of humid air, and the newly organised stormcentre moves eastward along its track, toward the region of the Mississippi Valley or the lakes. In doing so it descends the gradient of the plains through air of increasing density, and acquires greater energy every mile it advances. High pressures to the northward and southward of the storm-centre constantly feed it with fresh volumes of air, which being of different conditions of temperature and humidity, produce the rainfall that generally begins when the eastern margin of the depression enters the Missouri Valley. In the great region of the plains the storm finds free scope for development as well as an unfailing supply of atmospheric moisture. It usually attains its greatest energy when passing over Iowa, Illinois, Ohio, and Kentucky, toward the Upper Ohio Valley, and the narrow neck of territory between Lake Ontario and the Pennyslvanian section of the Alleghany Mountain Range. This mountain wall influences the course of the storm by deflecting it toward the north-east from the Middle Ohio Valley region, and thence over New England to Nova Scotia. The districts eastward of the Alleghany Mountains and southward of New York are rarely traversed by storm-centres coming as I have described, from the north-west, but receive the rainfall of the eastern margin of the storm as its centre passes north-eastward beyond the mountains, into the St. Lawrence Valley or the New England States.

But the mountains cause a profuse rainfall on their western slopes, and when the storm reaches the Atlantic the precipitation has been nearly exhausted. Its energy, therefore, decreases, when crossing from Oswego to Portland or Eastport, Maine, and does not recover until it receives from the Gulf Stream Region a new supply of humid air. I have endeavoured to describe the course of a storm-centre from the Pacific to the Atlantic, across the Continent, and have made no detailed explanation of the relation to its movement of the areas of high pressure. This I regard as of the highest importance, and will treat of fully uncler a special head. The course of the storm across the Atlantic, as well as its movement over Europe, will be governed only, I may say, by the high pressures. These being distributed from south to north, in a series of continuous, but movable zones, mark the directions of the storm's advance so clearly, as to enable an observer at this side of the ocean to predict with general accuracy, the section on the European coast on which the stormcentre will arrive, as well as the time of its arrival. Another type of Pacific storm is that which arrives on the southern and central section of the California coast as a great depression, and entering the continent, pours its rains over California, and becomes divided in to two sub-areas of low barometer by the Sierra Nevada range. One of these sub-areas, and nearly always the largest, takes a south-easterly direction across Southern Nevada, into Arizona, and crosses the Rocky Mountains in New Mexico to Northern Texas, where it is organised into a storm in the same manner, but much more rapidly, as the previously described area crossing into Montana. The other sub-area passes from Central California to Idaho, and thence across the Rocky Mountains, into the Yellowstone River Valley in Montana, pursuing a track, thereafter, which sometimes brings the depression into the Lower Missouri Valley, but usually towards the Upper Lake Region. This subarea of low pressure also becomes organised into a storm, but one of much less energy than that of Northern Texas. This can be accounted for by the fact that the crossing of the mountains by both sub-areas being almost simultaneous, the northern depression cannot receive any considerable atmospheric flow from the southward, as it is intercepted and drawn toward the southerly vortex. It sometimes occurs that the two centres of disturbance unite in a common depression west of the Mississippi River, but usually they preserve their identity, and become separated gradually by an intervening zone of relatively high barometer developed between them by their joint infuence. The northern centre moves away to the north-east, over the lakes and Canada, with diminishing energy, but the southern storm centre advances into the Lower Mississippi Valley, and soon dominates the weather conditions over all the region southward of the lakes. In this position its isobars extend eastward to the Georgia coast, and even into the Atlantic, but the centre moves towards the Obio Valley, westward of the Alleghany Mountains. The consequence is that a section of the clepression near the Atlantic coast is cut off by the high range of the Alleghanies, and another sub-area is formed which is speedily organised into a distinct storm centre by the impinging of the ondraught winds from the east, north-east, and south-east on the mountains, in the same manner as I have already described. 
As the centre of the main disturbance moves up the great central valley the subsidiary centre east of the Alleghanies moves with it, and where the mountains decrease in elevation the two centres draw towards each other so as to have a common encircling isobar of $29^{\circ} 60$ inches, and sometimes even less. When they reach the latitude of New York, storms of this type commonly leave the coast between latitudes $3^{\circ}$ and $42^{\circ}$, attended by an area of high pressure immediately to the northward, and followed by one from the south-west. The courses of these storms across the Atlantic are generally in comparatively low latitudes, and they arrive on the British Coasts from the west or south-west with moderate rains and winds backing from the north-east to the north-west.

Another type of Pacific storms is the one which originates in the tropical zone of that ocean, and strikes the Mexican coast, moving directly across that territory into Southern Texas, and along the Gulf Coast over Florida and Georgia to the Atlantic. The energy of such storms is frequently very great, and they retain, even after crossing the Mexican plateau, many of their original cyclonic features. When they move northeastward through the Mississippi Valley they are always attended by heary rains and electrical disturbances. Local storms or tornadoes are frequently developed on their south-eastern margins during the spring and summer months, and are always very destructive.

These Mexican storms, so called to distinguish them from the disturbances that move over Northern Texas from the California coast, will sometimes, but not often, cross the Alleghany Mountains from Tennessee to Virginia, and pass into the Atlantic northward of Cape Hatteras. Their courses across the Atlantic are generally southerly as compared with those of storms leaving Nova Scotia. They arrive on the British and French coasts from the south-west, but are now and then carried in a north-easterly direction, passing to the Norwegian coasts northward of Scotland, and thence over the Scandinavian Mountains into North-Eastern Russia and the Siberian Seas.

The cyclone, or great storm that originates in the equatorial zone of the Atlantic, by which I mean the region embraced between the equator and $15^{\circ} \mathrm{N}$. lat., possesses characteristics which mark it as the most destructive atmospheric disturbance known to meteorologists. Of course these storms are developed in the equatorial zones of other oceans, but are not of such immediate interest to us as the Atlantic cyclones. I am convinced that the conditions which combine to develop nearly all areas of low pressure have an equatorial origin, the exceptional cases being due to local liberations of terrestrial heat turing earthquakes and to the heating of volumes of air over great areas of sandy desert. North Atlantic cyclones may be dirided into four classes, namely: Those that originate near the Cape Verde Islands and make their northward curves east of the 35 th meridian, and do not affect the American coasts, but enter the European area over Morocco and Spain, passing eastward over the Mediterranean Sea. They are of comparatively rare occurrence. Secondly, those that originate about the 4oth, and curve northward east of the 8oth meridian, affecting the American coasts only by the induced marginal winds. Thirdly, those that originate immediately east of the Caribbee or Windward Islands, and perform their northward curves between the 8oth and goth meridians, so as to pass through the eastern part of the Gulf of Mexico, and over Alabama, Florida, Georgia, and the Carolinas toward the North Atlantic. Fourthly, those that originate nearer to the equator than the others referred to, and make the tremendous sweep from the middle of the ocean between the Venezuelan coast of South America and that of West Africa, over the West Indian Islands to the Texas coast, and there curving northward and eastward, sharply pass over the southern sections of the United States and into the North Atlantic from the vicinity of Cape Hatteras.

Of the first-named class of cyclones, little need be said beyond the reference already made. They represent the most serious dangers to be encountered by vessels bound to West African or South American ports, or passing over the Cape route to the Indian Ocean. The second class of cyclones, of which we have examples in the great storms of October 12, 1780, August 17, 1827, and August I2, I837, and the later one as traced by the United States Signal Service Bureau, which commenced about August 18, 1873, take northerly courses. The only land station where these can be accurately observed is that at Bermuda; therefore information regarding their energy and movements must be collected from the logs of ships that cross their tracks. It is believed that these storms are developed only in the midsummer, and are not of frequent occurrence, but on these points we have very little reliable information. I am, however, inclined to accept the statement as to their infrequency.

The third class of cyclones we are more familiar with, because it embraces that type of equatorial storm which we most frequently experience. Examples from the earlier meteorological records are the storms of August Io, 183r, and October 6, r846. With these we have the recent one of September 21,1877 , and which was signalled to London by the Herald Weather Bureau. The passage of this storm over the South Atlantic coast of the United States was attended by many disasters, wrecks, and inundations. Its course towards Europe was in comparatively low latitudes until it approached the Bay of Biscay, when it moved sharply north-eastward, causing heavy gales and rains, with thunder and lightning. The latter effects were very marked in Scotland.

The fourth class of cyclones, such as those of June 23, I831, and September 27, 1837, and later on September 21 , I875, known as the great Galveston cyclone, are usually of extraordinary violence. Among the first successes of the Herald Weather Bureau was the correct prediction of the course of this storm when it was moving westward over the Carribean Sea. Only on one instance within my observation has a cyclone of the third class passed northward on the western side of the Alleghany Mountains, and then the storm exhausted its energy in Canada, but its depression, though much contracted, reorganised into a minor disturbance when it passed into the Atlantic, off the New England coast. The tendency of cyclones to lose their force by the extension of their area of low pressure is more decided than in any other type of storm. This will account for the low degree of 
energy in disturbances evidently of equatorial origin when they reach the Pacific coast of the United States and the coast of Spain. Unless the direction of the zone of high pressure along the south margin on which they move forms an angle of more than forty-five degrees with the equator, the storm has a tendency to pass through it, and in doing so expends much of its energy.

(To be continued.)

JEROME J. COLLINS

\section{GAS AS FUEL}

A TTEMPTS have been made from time to time to use gas as a means for heating; these attempts have more frequently failed than stcceeded, chiefly by reason of the mechanical difficulties to be overcome.

It is pretty generally agreed that, on account of the ease with which the supply of a gaseous fuel can be regulated, the completeness with which such a fuel can be burned, the comparative readiness with which cleanliness can be maintained while using this fuel, and by reason of its high heating power, and for other reasons, gaseous fuel is to be much preferred to fuel in the solid form.

The most perfect gas for heating purposes would be that, the constituents of which should be all combustible, should be possessed of high thermal powers, and should produce, on burning, compounds of small specific heat. No gas which has yet been produced for use as fuel completely fulfils these conditions.

Common coal-gas contains such non-combustible bodies as carbondioxide and nitrogen, and among the products of its combustion is water, a body of large specific heat, and also requiring a considerable amount of heat to convert it into vapour. The complete combustion of coal gas also necessitates a comparatively large supply of air, and this, again, involves special mechanical appliances. Nevertheless, coal-gas has been proved to be, for certain purposes, a cheaper, more effective, and more easily managed fuel than coal, wood, or other forms of solid heat-giving material.

That steam is decomposed by hot carbon with the production of a gaseous mixture of considerable heating powers, has long been known, and several attempts have becn made to utilise the products of this decomposition. These attempts bave met with no great success on account of the cost of the plant required to work the manufacture and of the difficulties of the process. Long-continued experiments have, however, been carried on, and it would appear from a paper recently communicated to the Society of Arts by Mr. S. W. Davies, that these experiments have been crowned with a very fair measure of success.

The great difficulty was a mechanical one: it has been very simply overcome. Superheated steam is produced in a coil placed within a cylinder and is driven by its own tension in the form of a jet into the lower part of an anthracite fire. The jet of steam carries with it air sufficient to actively maintain the combustion of the anthracite; the gases issue at the top of the apparatus and pass into the mains. The fire is fed from the top by an arrangement which allows of the process being continuous. Water is forced into the coil under a pressure varying from $\mathrm{I} 5 \mathrm{lbs}$. to $40 \mathrm{lbs}$. on the square inch. The whole apparatus is compact and simple.
The products of the decomposition of steam by hot carbon are mainly hydrogen and carbon monoxide; traces of marsh gas are also formed. Could these gases be produced free from admixed non-combustible bodies we should have a gas of very high heating powers. But the temperature of the glowing carbon must be maintained by the introduction of oxygen, that is, in practice, by the introduction of air. The problem how to introduce air sufficient to keep up vigorous combustion, and at the same time to maintain the decomposition of the steam, appears to have been satisfactorily solved; but the introduction of air means a lowering of the heating power of the gas produced, inasmuch as four volumes of nitrogen are brought in along with every volume of oxygen supplied. By passing the gas through a series o vessels containing hot carbon the nitrogen may be very much diminished in amount, and the heating power of the gas proportionally increased.

The gas produced by the decomposition of steam by hot carbon always contains traces of carbon dioxide which is non-combustible; the amount of this compound may, however, be reduced to 3 or 4 per cent. by regulating the depth of the layer of hot carbon through which the gases pass, and by maintaining the temperature of that carbon at a high point. But the maintenance of a high temperature throughout a mass of carbon can be accomplished, under the conditions of the manufacture, only by introducing a rapid current of air, which again means a dilution of the gas produced.

If, therefore, means could be found forefeeding the anthracite fire with oxygen, a gas of very high heating power might be: produced. A supply of oxygen at a cheap rate is a great desideratum; the gas exists in practically unlimited quantity in the atmosphere, but an easy and successful method for separating it from the nitrogen with which it is there mixed is still only hoped for by the chemical manufacturer. Were a supply of oxygen forthcoming, mechanical difficulties would present themselves before it could be utilised in the production of "water gas." The introduction of too small an amount of oxygen would mean the non-decomposition of the whole of the steam and the cessation of the combustion of the anthracite; the introduction of too much oxygen would mean the production of carbon dioxide in considerable quantity. But by regulating the size of the steam jet and of the blast-pipe, these difficulties might probably be overcome.

As the gas is now produced all danger of explosion is removed.

The heating effect of the gas as at present manufactured is about one-fifth that of ordinary coal-gas, for equal volumes; but the cost of the gas is so much less than that of coal-gas, that a given amount of heating work may be done-according to the figures given in the paper referred to-by using the new gas, with a saving of from one-third to two-thirds of the expenditure which would be involved were coal-gás employed.

Although the new gas is not perfectly adapted for the purposes for which it is to be used, yet there can be little doubt that we are now a step, and a very considerable step, nearer the final solution of the problem. Doubtless improved furnaces, and improved apparatus generally for burning the improved fuel, will be introduced. 